Provided for non-commercial research and education use. Not for reproduction, distribution or commercial use.

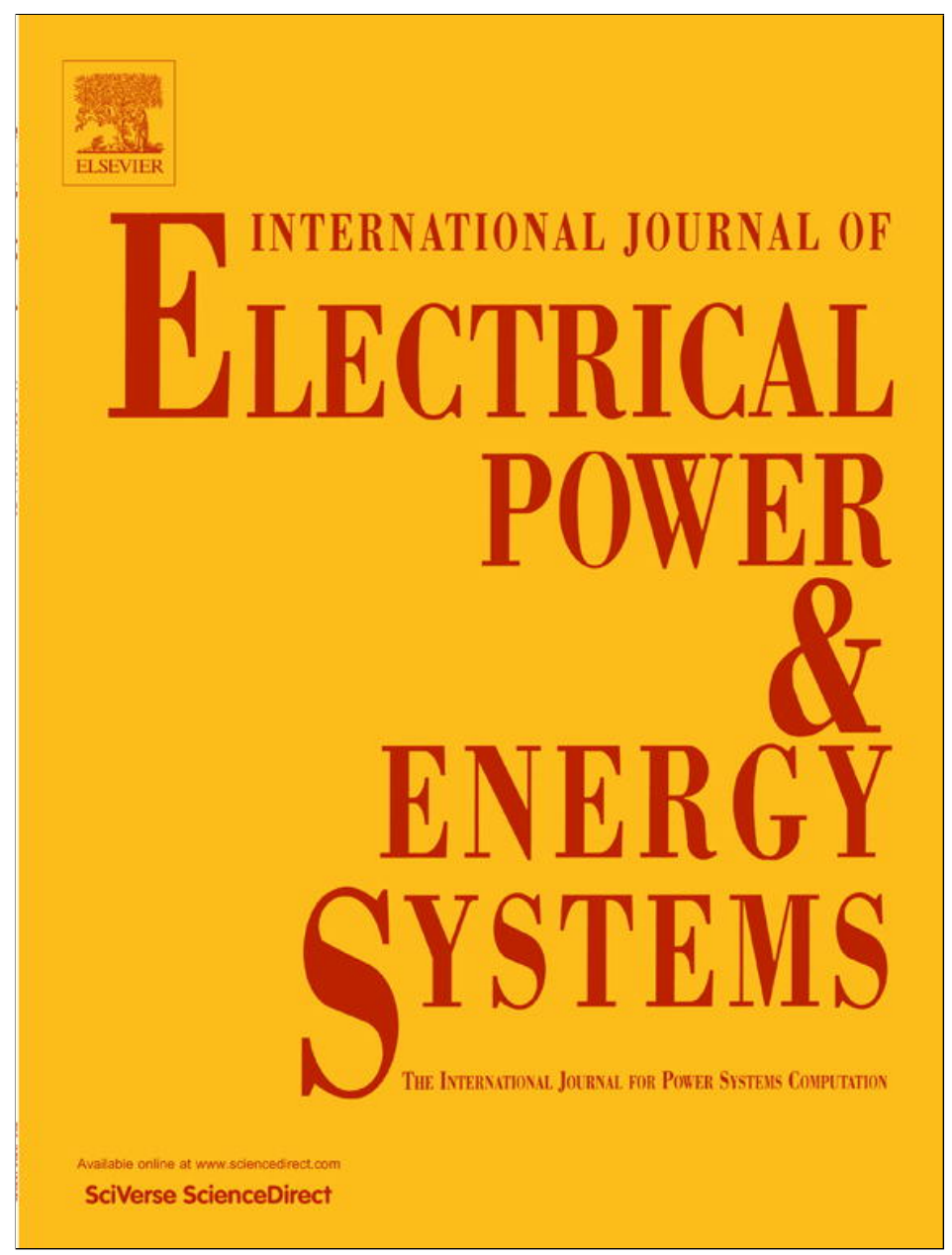

(This is a sample cover image for this issue. The actual cover is not yet available at this time.)

This article appeared in a journal published by Elsevier. The attached copy is furnished to the author for internal non-commercial research and education use, including for instruction at the authors institution and sharing with colleagues.

Other uses, including reproduction and distribution, or selling or licensing copies, or posting to personal, institutional or third party websites are prohibited.

In most cases authors are permitted to post their version of the article (e.g. in Word or Tex form) to their personal website or institutional repository. Authors requiring further information regarding Elsevier's archiving and manuscript policies are encouraged to visit:

http://www.elsevier.com/copyright 


\title{
Hybrid sensorless permanent magnet synchronous machine four quadrant drive based on direct matrix converter
}

\author{
Antoni Arias*, Carlos Ortega, Jordi Zaragoza, Jordi Espina, Josep Pou \\ Electronic Engineering Department, Universitat Politecnica de Catalunya, Colom 1, 08222 Terrassa, Catalonia, Spain
}

\section{A R T I C L E I N F O}

\section{Article history:}

Received 26 March 2012

Received in revised form 1 August 2012

Accepted 29 August 2012

\section{Keywords:}

Permanent magnet synchronous machines

Matrix converters

Sensorless control

Four quadrant servo drive

Voltage pulse test injection

\begin{abstract}
A B S T R A C T
Permanent Magnet Synchronous Machines (PMSMs) have several advantages, such as high efficiency and low volume and weight, which make them attractive for aerospace applications and high performance servo drives.

Matrix Converters (MCs) are an all-silicon alternative, with no bulky reactive elements, to the standard voltage source inverter.

The most common control technique for such PMSM MC-fed drives is the so-called Field-Oriented Control (FOC), which requires the permanent magnet flux position to achieve high dynamic performance. Encoders or resolvers are the most common sensing devices used for such a purpose, which not only increases the total cost of the PMSM drive but also adds extra electronics and cabling that may cause failures. This paper investigates and proposes an all range (from zero to full) speed hybrid sensorless FOC. The novelty of this paper relies on the use of a hybrid sensorless four quadrant FOC that averages the needed angle estimation from a model based angle estimator and a voltage pulse test injection angle estimator when feeding the PMSM with an MC instead of a standard voltage source inverter. Speed reversal and load impact simulation results are included, fully supporting the claims made in this paper.
\end{abstract}

(c) 2012 Elsevier Ltd. All rights reserved.

\section{Introduction}

Recently, there has been considerable interest in the use of Matrix Converter (MC) technology as an alternative to DC-voltage-link converters. In addition to regenerative power flow and sinusoidal input currents [1,2], MCs offer a number of advantages, including the potential for improved power density and the lack of significant energy storage elements, which have led onto interest in aerospace applications [3], compact motor drives [4] and renewable energy applications [5]. Despite the fact that MC technology is mature enough to produce dedicated IGBT modules available in a range of power levels [6,7] as well as commercial MC-fed drives [8], it still is a hot research topic when facing unexplored applications.

Permanent Magnet Synchronous Machines (PMSMs) have received increasing attention due to their higher power density, higher efficiency and better dynamic performance [9]. Accurate PMSM control requires rotor position information to realise the coordinate transformation of the vector control and to obtain speed and position feedback control signals. Optical encoders or magnetic resolvers are normally fitted to the machine shaft to

\footnotetext{
* Corresponding author. Tel.: +34 937398235; fax: +34 937398016.

E-mail addresses: antoni.arias@upc.edu (A. Arias), cortega@euss.es (C. Ortega), zaragoza@eel.upc.edu (J. Zaragoza), jordi.espina@upc.edu (J. Espina), josep.pou@ upc.edu (J. Pou).
}

directly measure this position variable. This has the disadvantages of adding to the total cost and size of the drive as well as reducing its reliability. For these reasons, significant research efforts have been put forth to achieve vector control of PMSMs without position sensors. These techniques can be broadly divided into model-based techniques, where the back-EMF of the machine is used for rotor Permanent Magnet (PM) flux detection, and injection techniques, where a probe signal, either high-frequency or voltage pulses, is used to track the machine saliencies and obtain the ultimate position.

Model-based techniques, e.g. [10-14], successfully achieve sensorless control at medium and high rotor speeds but fail at low excitation frequencies due to the reduction and eventual disappearance of the back-EMF induced by the rotor magnets at low rotor speeds.

The injection techniques can be mainly classified into two groups. The first one depends on the superposition of the fundamental voltage vector of a high-frequency injection either in the alpha/beta frame $[15,16]$ or in a rotating $d / q$ synchronous frame $[17,18]$, and the second one is based on a modification of the fundamental PWM pattern to include a voltage pulse test $[19,20]$.

For all injection methods to function, some level of machine saliency is necessary, which makes the technique straightforward for salient machines such as interior PMSMs but rather difficult when surface-mounted PMSMs are considered because they only have a low saliency due to stator tooth saturation. 


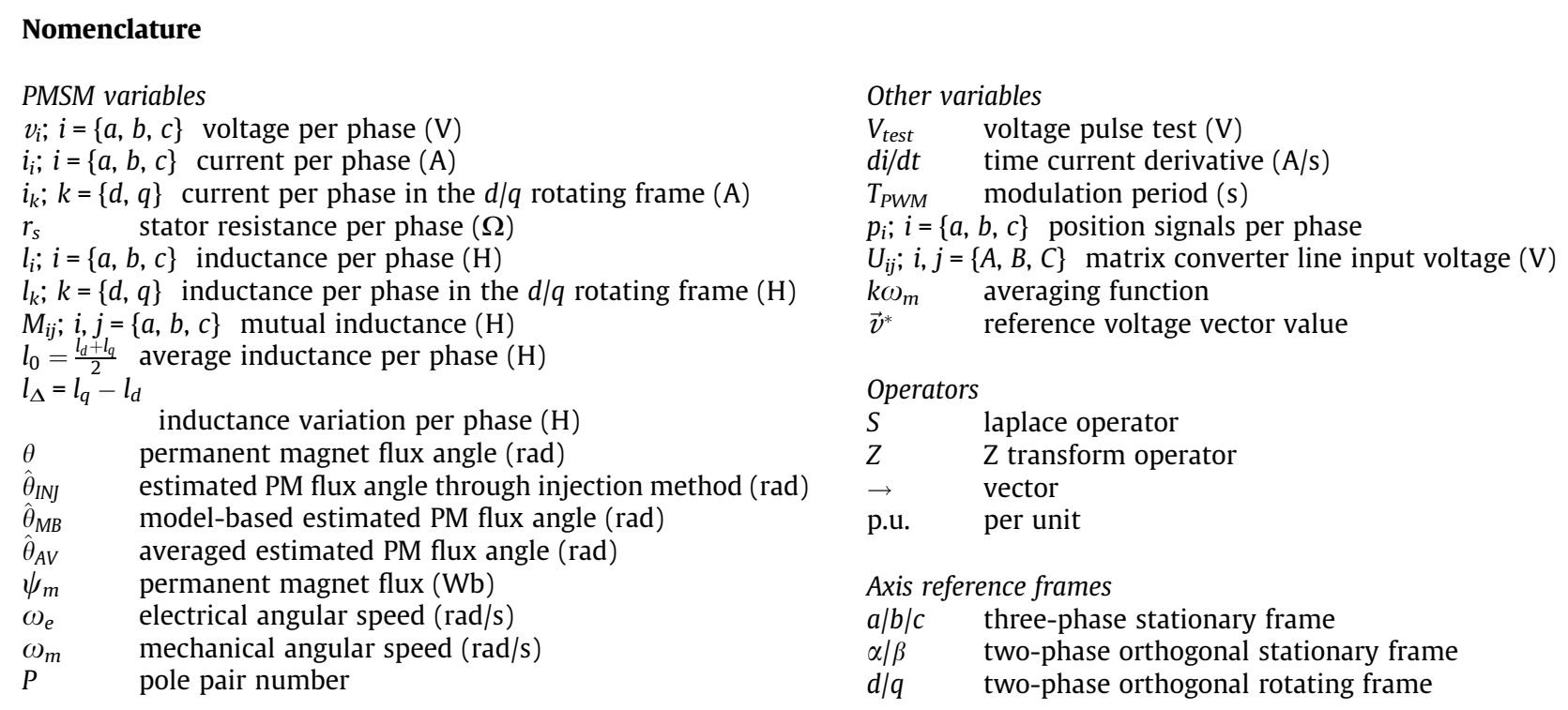

Several methods that combine the advantages of injection methods at low and zero speed and the lower losses and simplicity of the back-EMF integration at higher speeds have been proposed in the literature for both high- and low-saliency PMSMs [21-24].

In the present work, an MC-based hybrid sensorless FieldOriented Control (FOC) is proposed with a smooth transition from a non-model-based signal injection method at low speeds to a model-based flux estimator at higher speeds, combining the advantages of being able to properly work at low (even zero) speed and the lower losses and simplicity of the back-EMF integration at higher speeds. Another novelty of this work is the fact that an MC is used (instead of a Voltage Source Inverter) and that the voltage pulse test injection and the hybrid sensorless structure have been adapted to cover this unexplored application for such a converter. Moreover, the injection process based on MC presents the possibility of using smaller input voltages, and therefore a reduction of the inherent losses of such a method is achieved.

\section{Matrix converter as a bidirectional power converter}

An MC is a direct AC-AC converter, with $m \times n$ bidirectional switches, which connects an $m$-phase voltage source to an $n$-phase load. The most widely used configuration is the three-phase MC with $3 \times 3$ switches shown in Fig. $1[1,25,26]$. For simplicity and because of the lack of influence in the sensorless technique presented in the present paper, start-up and over-voltage protection circuits $[27,28]$ have been omitted.

The allowed switching states of a $3 \times 3 \mathrm{MC}$ are shown in Table 1 and have been classified into two different groups by applying space vector notation. The first group $( \pm 1 \ldots \pm 9)$ contains active vectors of variable amplitude, depending on the input voltages and the stationary position (pulsating vectors). The second group corresponds to the zero vectors $(O A, O B$ and $O C)$, which connect all of the output phases to the same input phase. Notice how Table 1 represents each MC vector in terms of output voltage and input current to fully exploit the inherent four-quadrant MC capability. Therefore, each vector will be considered in terms of the voltage at the output to control the load, and the main input current will be sinusoidal and in phase with the input voltage (input power factor equal to 1 ).

\section{Fundamentals of the voltage pulse test injection estimation algorithm}

\subsection{Surface-mounted PMSM saliency}

Surface-mounted PMSMs, as shown in (1), have a low saliency mainly due to stator saturation from the main PM.

$\left[\begin{array}{l}v_{a} \\ v_{b} \\ v_{c}\end{array}\right]=r_{s}\left[\begin{array}{l}i_{a} \\ i_{b} \\ i_{c}\end{array}\right]+\frac{d}{d t}\left[\left[\begin{array}{ccc}l_{a} & M_{a b} & M_{a c} \\ M_{b a} & l_{b} & M_{b c} \\ M_{c a} & M_{c b} & l_{c}\end{array}\right]\left[\begin{array}{c}i_{a} \\ i_{b} \\ i_{c}\end{array}\right]+\Psi_{m}\left[\begin{array}{c}\cos (\theta) \\ \cos \left(\theta-\frac{2 \pi}{3}\right) \\ \cos \left(\theta-\frac{4 \pi}{3}\right)\end{array}\right]\right]$

Such saliency is modelled as a sinusoidal spatial variation of the stator inductances [20] and can be mathematically expressed as (2)(4).

$l_{a}=l_{0}-l_{\Delta} \cos (2 \cdot P \cdot \theta)$

$l_{b}=l_{0}-l_{\Delta} \cos (2 \cdot P \cdot(\theta-2 \pi / 3))$

$l_{c}=l_{0}-l_{\Delta} \cos (2 \cdot P \cdot(\theta-4 \pi / 3))$

Whenever the PM is close to any phase, its inductance will be affected by a larger concatenated magnetic field and will therefore be more saturated. Hence, the PMSM inductance values will vary

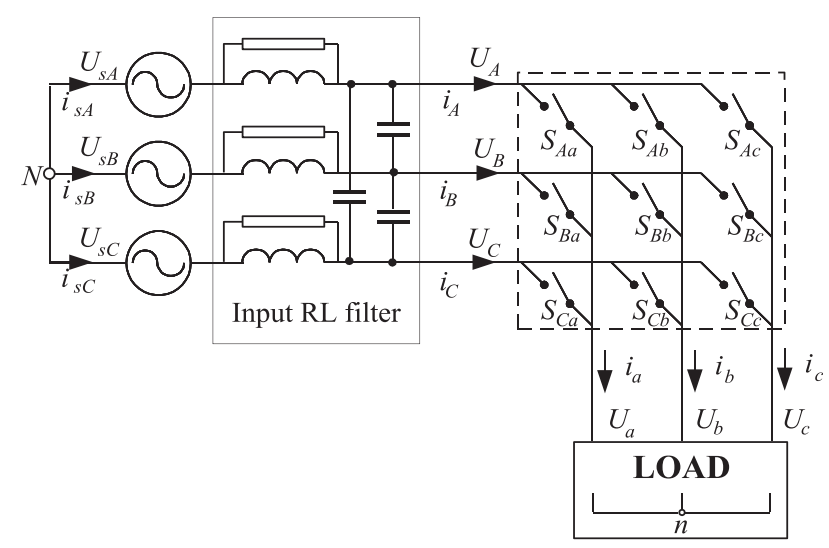

Fig. 1. Matrix converter scheme. 
Table 1

Matrix converter output voltage and input current space vectors.

\begin{tabular}{llllll}
\hline State & a b c & $|\vec{V} o|$ & $\alpha_{\boldsymbol{o}}$ & $\left|\overrightarrow{\boldsymbol{i}}_{i}\right|$ & $\beta_{i}$ \\
\hline+1 & A B B & $2 / 3 U_{A B}$ & 0 & $2 / \sqrt{3} i_{a}$ & $11 \pi / 6$ \\
-1 & B A A & $-2 / 3 U_{A B}$ & 0 & $-2 / \sqrt{3} i_{a}$ & $11 \pi / 6$ \\
+2 & B C C & $2 / 3 U_{B C}$ & 0 & $2 / \sqrt{3} i_{a}$ & $\pi / 2$ \\
-2 & C B B & $-2 / 3 U_{B C}$ & 0 & $-2 / \sqrt{3} i_{a}$ & $\pi / 2$ \\
+3 & C A A & $2 / 3 U_{C A}$ & 0 & $2 / \sqrt{3} i_{a}$ & $7 \pi / 6$ \\
-3 & A C C & $-2 / 3 U_{C A}$ & 0 & $-2 / \sqrt{3} i_{a}$ & $7 \pi / 6$ \\
+4 & B A B & $2 / 3 U_{A B}$ & $2 \pi / 3$ & $2 / \sqrt{3} i_{b}$ & $11 \pi / 6$ \\
-4 & A B A & $-2 / 3 U_{A B}$ & $2 \pi / 3$ & $-2 / \sqrt{3} i_{b}$ & $11 \pi / 6$ \\
+5 & C B C & $2 / 3 U_{B C}$ & $2 \pi / 3$ & $2 / \sqrt{3} i_{b}$ & $\pi / 2$ \\
-5 & B C B & $-2 / 3 U_{B C}$ & $2 \pi / 3$ & $-2 / \sqrt{3} i_{b}$ & $\pi / 2$ \\
+6 & A C A & $2 / 3 U_{C A}$ & $2 \pi / 3$ & $2 / \sqrt{3} i_{b}$ & $7 \pi / 6$ \\
-6 & C A C & $-2 / 3 U_{C A}$ & $2 \pi / 3$ & $-2 / \sqrt{3} i_{b}$ & $7 \pi / 6$ \\
+7 & B B A & $2 / 3 U_{A B}$ & $4 \pi / 3$ & $2 / \sqrt{3} i_{c}$ & $\pi / 6$ \\
-7 & A A B & $-2 / 3 U_{A B}$ & $4 \pi / 3$ & $-2 / \sqrt{3} i_{c}$ & $\pi / 6$ \\
+8 & C C B & $2 / 3 U_{B C}$ & $4 \pi / 3$ & $2 / \sqrt{3} i_{c}$ & $\pi / 2$ \\
-8 & B B C & $-2 / 3 U_{B C}$ & $4 \pi / 3$ & $-2 / \sqrt{3} i_{c}$ & $\pi / 2$ \\
+9 & A A C & $2 / 3 U_{C A}$ & $4 \pi / 3$ & $2 / \sqrt{3} i_{c}$ & $7 \pi / 6$ \\
-9 & C C A & $-2 / 3 U_{C A}$ & $4 \pi / 3$ & $-2 / \sqrt{3} i_{c}$ & $7 \pi / 6$ \\
$0 A$ & A A A & 0 & - & 0 & - \\
$0 B$ & B B B & 0 & - & 0 & - \\
$0 C$ & C C C & 0 & - & 0 & - \\
\hline & & & & & \\
\hline
\end{tabular}

as Fig. 2 illustrates, where $l_{d}$ and $l_{q}$ are the equivalent inductances (after applying to the PMSM model, firstly the $a / b / c$ to $\alpha / \beta$ and secondly the $\alpha / \beta$ to $d / q$ axis transformations).

The injection algorithm consists in calculating this inductancevarying value by means of firstly imposing a known voltage pulse test $\left(V_{\text {test }}\right)$ and secondly measuring the consequent $d i / d t$ (by means of a non-integrating Rogowski coil [29]). This two-magnitude division will provide the inductance-varying value, as Fig. 3 illustrates.

\subsection{Tracking the saliency}

Provided that this sensorless technique will be used at low and zero speed, the back-EMF component of the machine model introduced in (1) may be negligible. Moreover, if the voltage test pulse vectors are injected for a small period of time without altering the fundamental component, as will be introduced later, the PMSM can be further simplified to its high-frequency model with just stator inductances in which the stator resistance voltage drop can be neglected. When the MC vector is +1 , the output voltage is $U_{A B}$, as Fig. 4 shows, and the neutral point voltage $U_{n}(5)$ may be easily deduced.

$U_{n}=U_{A B} \frac{\frac{l_{b} \cdot l_{c}}{l_{b}+l_{c}}}{l_{a}+\frac{l_{b} \cdot l_{c}}{l_{b}+l_{c}}}=U_{A B} \frac{l_{b} \cdot l_{c}}{l_{a} \cdot l_{b}+l_{a} \cdot l_{c}+l_{b} \cdot l_{c}}$

Under such an MC vector, the three-phase current derivative values would be as indicated in (6)-(8).

$\frac{d i_{a}(+1)}{d t}=\frac{U_{A B}-U_{n}}{l_{a}}=U_{A B} \cdot \frac{l_{b}+l_{c}}{l_{a} \cdot l_{b}+l_{a} \cdot l_{c}+l_{b} \cdot l_{c}}$

$\frac{d i_{b}(+1)}{d t}=-\frac{U_{n}}{l_{b}}=-U_{A B} \cdot \frac{l_{c}}{l_{a} \cdot l_{b}+l_{a} \cdot l_{c}+l_{b} \cdot l_{c}}$

$\frac{d i_{c}(+1)}{d t}=-\frac{U_{n}}{l_{c}}=-U_{A B} \cdot \frac{l_{b}}{l_{a} \cdot l_{b}+l_{a} \cdot l_{c}+l_{b} \cdot l_{c}}$

Substituting Eqs. (2)-(4) into (6)-(8), the following expressions are obtained [20]:

$\frac{d i_{a}(+1)}{d t}=\frac{U_{A B}}{g} \cdot\left(2-\frac{l_{\Delta}}{l_{0}} \cos (2 \cdot P \cdot \theta)\right)$

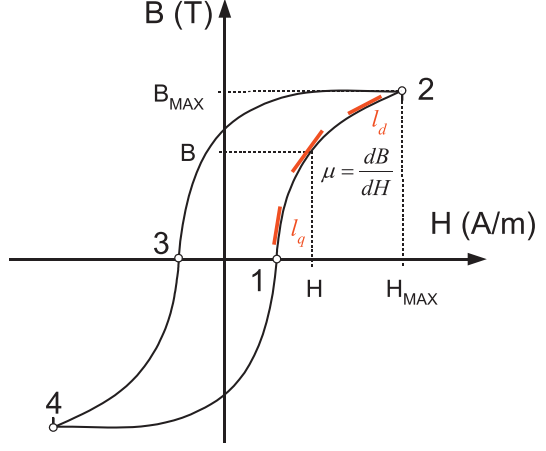

Fig. 2. Magnetic saturation curve showing how the same magnetic material can have a different permeability $(\mu)$ and therefore inductance (la). In the high magnetic field limit, any further increase in magnetic field strength $(H)$ will result in no further change in the magnetic flux density $(B)$.
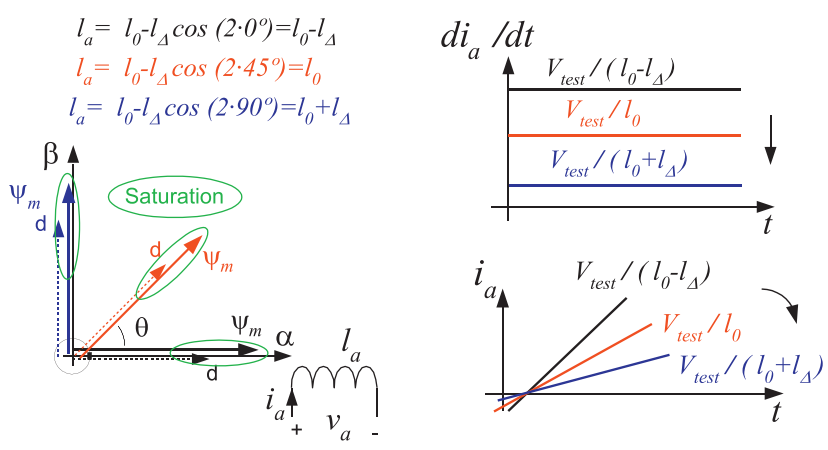

Fig. 3. Left: $l_{a}$ saturation effect and its sinusoidal spatial variation depending on the PM position. Right: different di/dt values depending on the PM position to be measured with a Rogowski coil.

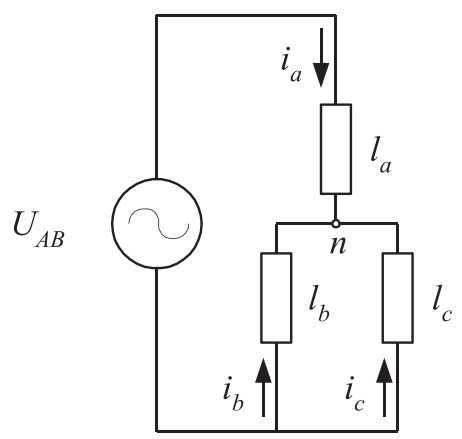

Fig. 4. High-frequency equivalent PMSM model connected to a matrix converter when the MC output voltage vector is +1 .

$$
\begin{aligned}
& \frac{d i_{b}(+1)}{d t}=-\frac{U_{A B}}{g} \cdot\left(1+\frac{l_{\Delta}}{l_{0}} \cos \left(2 \cdot P \cdot\left(\theta-\frac{4 \pi}{3}\right)\right)\right) \\
& \frac{d i_{c}(+1)}{d t}=-\frac{U_{A B}}{g} \cdot\left(1+\frac{l_{\Delta}}{l_{0}} \cos \left(2 \cdot P \cdot\left(\theta-\frac{2 \pi}{3}\right)\right)\right)
\end{aligned}
$$

where:

$g=3 l_{\sigma 0}\left(1-\frac{l_{\Delta}^{2}}{4 l_{0}^{2}}\right)$

The permanent magnet position signal can be defined as in (13). 


$$
\begin{aligned}
\vec{p}_{P M}= & p_{a}+e^{j 2 \pi / 3} \cdot p_{b}+e^{j 4 \pi / 3} \cdot p_{c} \\
= & \frac{2}{3} \\
& \times \frac{l_{\Delta}}{l_{0}}\left[\cos (2 P \theta)+e^{j 2 \pi / 3} \cos \left(2 P\left(\theta-\frac{2 \pi}{3}\right)\right)+e^{j 4 \pi / 3} \cos \left(2 P\left(\theta-\frac{4 \pi}{3}\right)\right)\right]
\end{aligned}
$$

Considering the phase position signals $p_{a}, p_{b}$ and $p_{c}$ as defined in (13) together with expressions (9)-(11), expressions (14)-(16), are obtained, which relate the current derivatives, which depend on the PM position and the position signals for further angle estimation.

$$
\begin{aligned}
& p_{a}=-\frac{g}{U_{A B}} \frac{d i_{a}(+1)}{d t}+2 \\
& p_{b}=-\frac{g}{U_{A B}} \frac{d i_{c}(+1)}{d t}-1 \\
& p_{c}=-\frac{g}{U_{A B}} \frac{d i_{b}(+1)}{d t}-1
\end{aligned}
$$

For the remaining MC vectors, the position signals are worked out in Table 2 .

\subsection{Test Voltage Injection through a PWM Sequence}

To measure the current derivatives, the switching PWM pattern must be changed. In this research, a double-sided SVM is used in which the modulation period ( $\left.T_{P W M}\right)$ has been set to $80 \mu \mathrm{s}$ and the pulse voltage test vector, which has been fitted in this PWM pattern, is applied for $5 \mu \mathrm{s}$. In order to not alter the fundamental PWM sequence, the positive and negative MC voltage vectors are applied right in the middle [30] of the double-sided PWM switching pattern described in [31], as Fig. 5 shows, for the beginning of input sector 1 .

Test voltages always introduce a distortion in the load phase currents, worsening the total harmonic distortion values and increasing the ripple. Some authors have minimised this distortion by trying to use the PWM voltages to measure the current derivative [32]. Whenever the PWM active vectors are too short in time, which happens rather frequently at low or zero speed, the PWM pattern is also altered by increasing the length of the same selected active vectors [32]. Despite the fact that almost all MC applications consider only the largest input voltages, in this research, the distortion caused by the test voltage is minimised by using medium test MC voltage vectors, which was a good compromise between small distortion and voltage test injection, as reported in [33].

Once the PWM double-sided pattern is modified as shown in Fig. 5, without altering the fundamental PWM, which is achieved by the positive and negative MC voltage vectors, two current derivative (di/dt) signals per phase (i.e., six in total) must be measured. Finally, the so-called position signals for phases $a, b$ and $c$ might be obtained as Eqs. (17)-(19) indicate.

$p_{a}=\frac{g}{U_{A B}} \frac{d i_{a}(+1)}{d t}+2-\frac{g}{U_{A B}} \frac{d i_{a}(-1)}{d t}+2$

$p_{b}=\frac{g}{U_{A B}} \frac{d i_{c}(+1)}{d t}-1-\frac{g}{U_{A B}} \frac{d i_{c}(-1)}{d t}-1$

$p_{c}=\frac{g}{U_{A B}} \frac{d i_{b}(+1)}{d t}-1-\frac{g}{U_{A B}} \frac{d i_{b}(-1)}{d t}-1$

Position signals for phases $a, b$ and $c$ are transformed to $\alpha$ and $\beta$ position signals, and by means of the arc tangent function, the PM angle $\left(\hat{\theta}_{I N J}\right)$ is properly estimated.

\begin{tabular}{|c|c|c|}
\hline$p_{a}=-\frac{g}{U_{A B}} \frac{d i_{a}(+1)}{d t}+2$ & $p_{c}=-\frac{g}{U_{A B}} \frac{d i_{b}(+1)}{d t}-1$ & $p_{b}=-\frac{g}{U_{A B}} \frac{d i_{c}(+1)}{d t}-1$ \\
\hline$p_{a}=\frac{g}{U_{A B}} \frac{d i_{a}(-1)}{d t}+2$ & $p_{c}=\frac{g}{U_{A B}} \frac{d i_{b}(-1)}{d t}-1$ & $p_{b}=\frac{g}{U_{A B}} \frac{d i_{c}(-1)}{d t}-1$ \\
\hline$p_{a}=-\frac{g}{U_{B C}} \frac{d i_{a}(+2)}{d t}+2$ & $p_{c}=-\frac{g}{U_{B C}} \frac{d i_{b}(+2)}{d t}-1$ & $p_{b}=-\frac{g}{U_{B C}} \frac{d i_{c}(+2)}{d t}-1$ \\
\hline$p_{a}=\frac{g}{U_{B C}} \frac{d i_{a}(-2)}{d t}+2$ & $p_{c}=\frac{g}{U_{B C}} \frac{d i_{b}(-2)}{d t}-1$ & $p_{b}=\frac{g}{U_{B C}} \frac{d i_{c}(-2)}{d t}-1$ \\
\hline$p_{a}=-\frac{g}{U_{C A}} \frac{d i_{a}(+3)}{d t}+2$ & $p_{c}=-\frac{g}{U_{C A}} \frac{d i_{b}(+3)}{d t}-1$ & $p_{b}=-\frac{g}{U_{C A}} \frac{d i_{c}(+3)}{d t}-1$ \\
\hline$p_{a}=\frac{g}{U_{C A}} \frac{d i_{a}(-3)}{d t}+2$ & $p_{c}=\frac{g}{U_{C A}} \frac{d i_{b}(-3)}{d t}-1$ & $p_{b}=\frac{g}{U_{C A}} \frac{d i_{c}(-3)}{d t}-1$ \\
\hline$p_{c}=-\frac{g}{U_{A B}} \frac{d i_{a}(+4)}{d t}-1$ & $p_{b}=-\frac{g}{U_{A B}} \frac{d i_{b}(+4)}{d t}+2$ & $p_{a}=-\frac{g}{U_{A B}} \frac{d i_{c}(+4)}{d t}-1$ \\
\hline$p_{c}=\frac{g}{U_{A B}} \frac{d i_{a}(-4)}{d t}-1$ & $p_{b}=\frac{g}{U_{A B}} \frac{d i_{b}(-4)}{d t}+2$ & $p_{a}=\frac{g}{U_{A B}} \frac{d i_{c}(-4)}{d t}-1$ \\
\hline$p_{c}=-\frac{g}{U_{B C}} \frac{d i_{a}(+5)}{d t}-1$ & $p_{b}=-\frac{g}{U_{B C}} \frac{d i_{b}(+5)}{d t}+2$ & $p_{a}=-\frac{g}{U_{B C}} \frac{d i_{c}(+5)}{d t}-1$ \\
\hline$p_{c}=\frac{g}{U_{B C}} \frac{d i_{a}(-5)}{d t}-1$ & $p_{b}=\frac{g}{U_{B C}} \frac{d i_{b}(-5)}{d t}+2$ & $p_{a}=\frac{g}{U_{B C}} \frac{d i_{C}(-5)}{d t}-1$ \\
\hline$p_{c}=-\frac{g}{U_{C A}} \frac{d i_{a}(+6)}{d t}-1$ & $p_{b}=-\frac{g}{U_{C A}} \frac{d i_{b}(+6)}{d t}+2$ & $p_{a}=-\frac{g}{U_{C A}} \frac{d i_{c}(+6)}{d t}-1$ \\
\hline$p_{c}=\frac{g}{U_{C A}} \frac{d i_{a}(-6)}{d t}-1$ & $p_{b}=\frac{g}{U_{C A}} \frac{d i_{b}(-6)}{d t}+2$ & $p_{a}=\frac{g}{U_{C A}} \frac{d i_{c}(-6)}{d t}-1$ \\
\hline$p_{b}=-\frac{g}{U_{A B}} \frac{d i_{a}(+7)}{d t}-1$ & $p_{a}=-\frac{g}{U_{A B}} \frac{d i_{b}(+7)}{d t}-1$ & $p_{c}=-\frac{g}{U_{A B}} \frac{d i_{c}(+7)}{d t}+2$ \\
\hline$p_{b}=\frac{g}{U_{A B}} \frac{d i_{a}(-7)}{d t}-1$ & $p_{a}=\frac{g}{U_{A B}} \frac{d i_{b}(-7)}{d t}-1$ & $p_{c}=\frac{g}{U_{A B}} \frac{d i_{c}(-7)}{d t}+2$ \\
\hline$p_{b}=-\frac{g}{U_{B C}} \frac{d i_{a}(+8)}{d t}-1$ & $p_{a}=-\frac{g}{U_{B C}} \frac{d i_{b}(+8)}{d t}-1$ & $p_{c}=-\frac{g}{U_{B C}} \frac{d i_{c}(+8)}{d t}+2$ \\
\hline$p_{b}=\frac{g}{U_{B C}} \frac{d i_{a}(-8)}{d t}-1$ & $p_{a}=\frac{g}{U_{B C}} \frac{d i_{b}(-8)}{d t}-1$ & $p_{c}=\frac{g}{U_{B C}} \frac{d i_{c}(-8)}{d t}+2$ \\
\hline$p_{b}=-\frac{g}{U_{C A}} \frac{d i_{a}(+9)}{d t}-1$ & $p_{a}=-\frac{g}{U_{C A}} \frac{d i_{b}(+9)}{d t}-1$ & $p_{c}=-\frac{g}{U_{C A}} \frac{d i_{c}(+9)}{d t}+2$ \\
\hline$p_{b}=\frac{g}{U_{C A}} \frac{d i_{a}(-9)}{d t}-1$ & $p_{a}=\frac{g}{U_{C A}} \frac{d i_{b}(-9)}{d t}-1$ & $p_{c}=\frac{g}{U_{C A}} \frac{d i_{c}(-9)}{d t}+2$ \\
\hline
\end{tabular}

It should be mentioned that one of the inconveniences of this angle estimation technique when using MCs instead of conven-
Table 2

Position signals for matrix converter voltage test vectors and star-connected machines.

tional voltage source inverters is that the position signals rely on the variable input voltage pulse test instead of a constant DC link voltage. Therefore, the actual voltages imposed during the voltage pulse test must be accurately known.

\section{Model-based estimation}

A voltage model [34] is proposed in this work to estimate the PM flux vector. Once the PM vector is correctly estimated, the PM angle is obtained by the arc tangent function of its $\alpha$ and $\beta$ components. From Eq. (1), using the space vector notation and isolating the PM flux, Eq. (20) is derived, which can be understood as the integration of the back-EMF caused by the PM flux time variation, disregarding any voltage created by the stator flux from the stator currents. To protect the PM and keep it constant, the field-oriented control will keep the direct current component $\left(i_{d}\right)$ equal to 0 ; therefore, the stator flux is only created from the quadrature current component $\left(i_{q}\right)$ and is proportional to the $l_{q}$ value, as written in Eq. (20). In practical implementations, the currents are provided from actual measured values, but the voltages are not measured because they are PWMs. Therefore, the fundamental reference voltage value $\left(\vec{v}^{*}\right)$ is used instead.

$\vec{\psi}_{m}=\int\left(\vec{v}^{*}-r_{s} \cdot \vec{i}\right) d t-l_{q} \cdot \vec{i}$

To avoid the drifting caused by a pure integrator, a Low-Pass (LP) filter, as illustrated in Fig. A1, is used instead. However, the use of such a LP filter limits the effectiveness of the model from well above the cut-off frequency (one decade, ideally) to the nominal one. Below that, the delay introduced by the LP filter and the gain are too different from those of the pure integrator. In reality, the LP filter's phase response is characterised from $60 \pi \mathrm{rad} / \mathrm{s}$ up to $300 \pi \mathrm{rad} / \mathrm{s}$, and such a characterised delay is considered for the final PM flux angle estimation.

Still, the DC and low-frequency components are present in the PM flux estimation; therefore, the need to filter them with a second High-Pass (HP) first-order filter, shown in Fig. A2, arises. As before, the delay phase shift is characterised and compensated when the actual PM flux angle is estimated. 


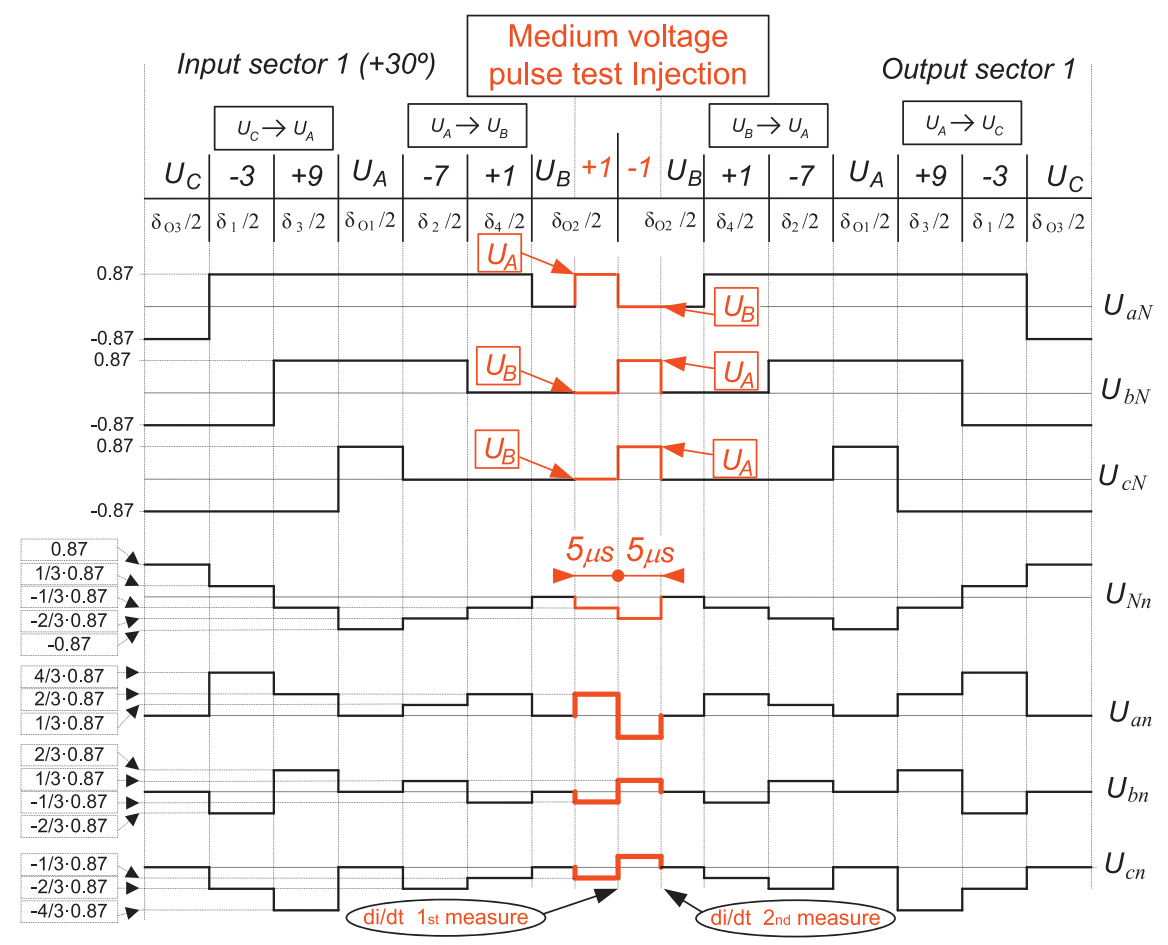

Fig. 5. Double-sided SVM commutation period $\left(T_{P W M}\right)$ pattern with medium voltage pulse test injection for the end of input sector $1\left(+30^{\circ}\right)$ and output sector 1 .

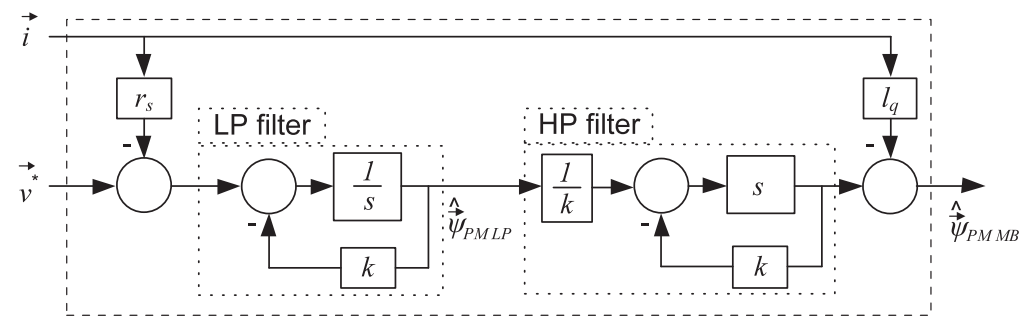

Fig. 6. Model-based PM flux vector estimation scheme.

Finally, the PM estimated angle $\left(\hat{\theta}_{M B}\right)$ is calculated with the arc tangent function as Eq. (21) indicates.

$\hat{\theta}_{M B}(k)=\arctan \left(\frac{\hat{\psi}_{\mathrm{PMMB}_{\beta}}(k)}{\hat{\psi}_{\mathrm{PMMB}_{\alpha}}(k)}\right)$

The overall scheme of the model-based estimation with both filtering processes is shown in Fig. 6.

\section{Hybrid sensorless field-oriented control system}

The hybrid system involves both the previously presented model-based estimation angle and that obtained from the voltage pulse test signal injection.

At high speeds, the model-based estimation yields good angle estimation. In contrast, at low speeds, the model-based estimation becomes inefficient due to a lack of back-EMF and an unfavourable signal to noise ratio; therefore, at low speeds, the hybrid system should only employ the injection technique.

The transition between both estimations is smoothly performed through the averaging equation written in (22),

$\hat{\theta}_{A V}=\left(k \varpi_{m} \cdot \hat{\theta}_{M B}\right)+\left(\left(1-k \varpi_{m}\right) \cdot \hat{\theta}_{I N J}\right)$

where $k \omega_{m}$ is the averaging function, which mainly has a value varying between $20 \%$ and $40 \%$ of the nominal speed, as Fig. 7 illus- trates. Above $40 \%$ and below $20 \%$, only the model-based and the injection estimations are respectively used.

Because the pulse test signal injection introduces extra losses and distortions, the hybrid system will stop such an injection at high speeds once the model-based estimation itself yields good accuracy. Hence, the ON/OFF injection function is also defined in Fig. 7.

The hybrid sensorless field-oriented control scheme has been tested with an off-the-shelf PMSM, whose parameters are listed in Table 3, and the speed and current loops are closed, as shown in Fig. 8. The simulation model includes not only all PI regulators and the PMSM model but also an accurate model of the matrix converter with the input filter and the space vector modulation. Moreover, one PWM period delay was considered in all sensorless control simulations.

The current loop is closed every $80 \mu$ s and the outer speed loop every $4.96 \mathrm{~ms}$. The current and speed PIs are tuned with the root locus pole assignment technique to fulfil the following specifications:

- Damping factor equal to 0.707 , i.e., $5 \%$ of overshoot.

- Settling time (to within $2 \%$ of the final value) of $4 \mathrm{~ms}$ for the current loop and $0.4 \mathrm{~s}$ for the speed loop.

A pre-filter is introduced in the reference values to avoid an unwanted transient response due to the zero introduced by the PI. 

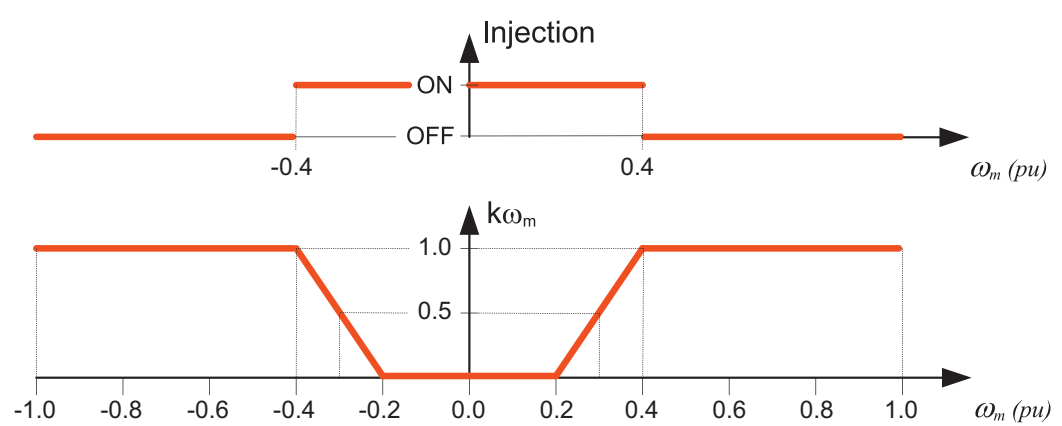

Fig. 7. Averaging function for the model-based and injection PM angle estimations and the ON/OFF injection function.

Table 3

Surface-mounted permanent magnet synchronous machine.

\begin{tabular}{ll}
\hline Rated power/paired poles & $3.8 \mathrm{~kW} / 3$ \\
Nominal speed/rated torque & $314.15 \mathrm{rad} / \mathrm{s} / 12.2 \mathrm{~N} \mathrm{~m}$ \\
$\mathrm{Rs} / \mathrm{Ld} / \mathrm{Lq} /$ saliency & $0.5 \Omega / 4.35 \mathrm{mH} / 5.9 \mathrm{mH} / 0.73$ \\
\hline
\end{tabular}

\section{Results}

All numerical results have been carried out with Matlab/Simulink software. Only the estimated position and speed values are used for the current and speed control loops since the system was in sensorless conditions from the start up.

\subsection{Speed reversal}

Figs. 9 and 10 illustrate the performance under a stepwise full speed change $( \pm 3000 \mathrm{rpm})$ with no load and full load $(12.2 \mathrm{Nm})$, respectively, under the hybrid sensorless field-oriented control. In both tests, the angle error is kept at all times to within \pm 4.5 electrical degrees ( \pm 1.5 mechanical degrees).

The largest angle error figures are present when $i_{q}$ (i.e., torque) takes the maximum of $200 \%$ of its nominal value, which is never held for periods longer than $1.5 \mathrm{~s}$.

In both cases, the tests are undertaken in the four quadrants, i.e., for both motor and generator operating modes. It must be pointed out that the largest angle error figures arise for the maximum $i_{q}$ current only when the PMSM is in the motor mode in both quadrants 1 and 3, but never when it is in the generator mode.

\subsection{Load Impact}

The second experiment involves full load impact tests with three different speeds, zero speed in Fig. 11, 30\% in Fig. 12 and full speed in Fig. 13. During the zero and full speed load impact tests, only one sensorless method, the injection and the model-based
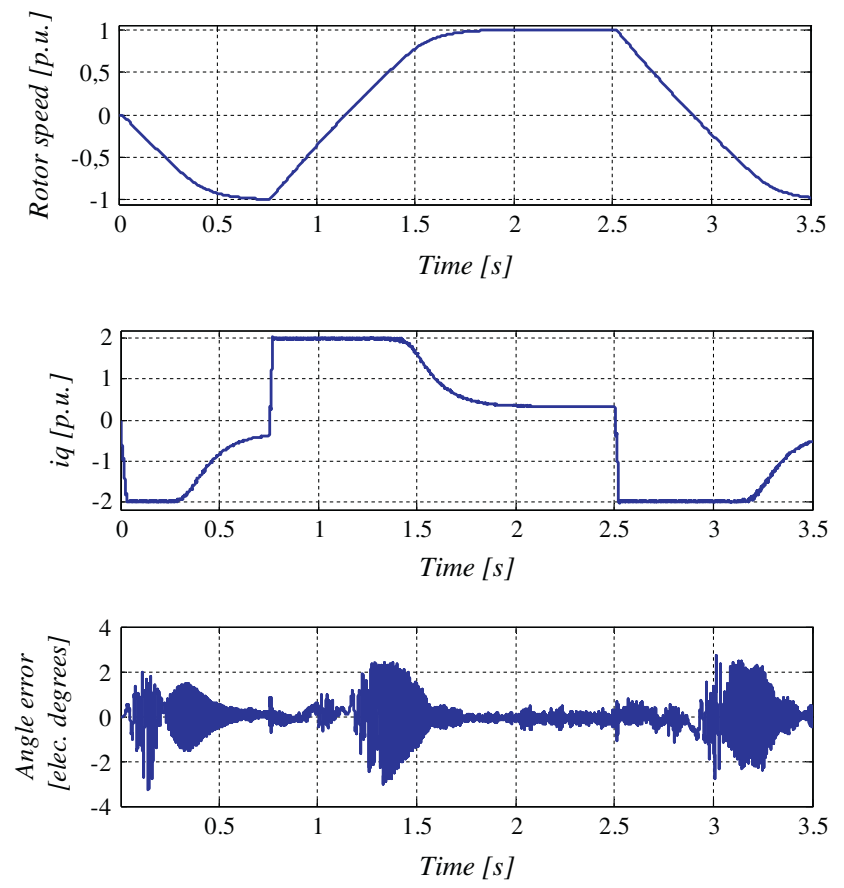

Fig. 9. Sensorless full speed reversal under no load. From top to bottom: estimated speed per unit, quadrature current component per unit and angle error in electrical degrees.

method, respectively, is operating. In contrast, when the load impact is performed at $30 \%$ of the speed, the hybrid system employs the average of both methods.

As Figs. 11-13 illustrate, the hybrid sensorless FOC performance is excellent because the angle error is kept at figures smaller than \pm 2.0 electrical degrees $( \pm 0.67$ mechanical degrees) under all conditions.

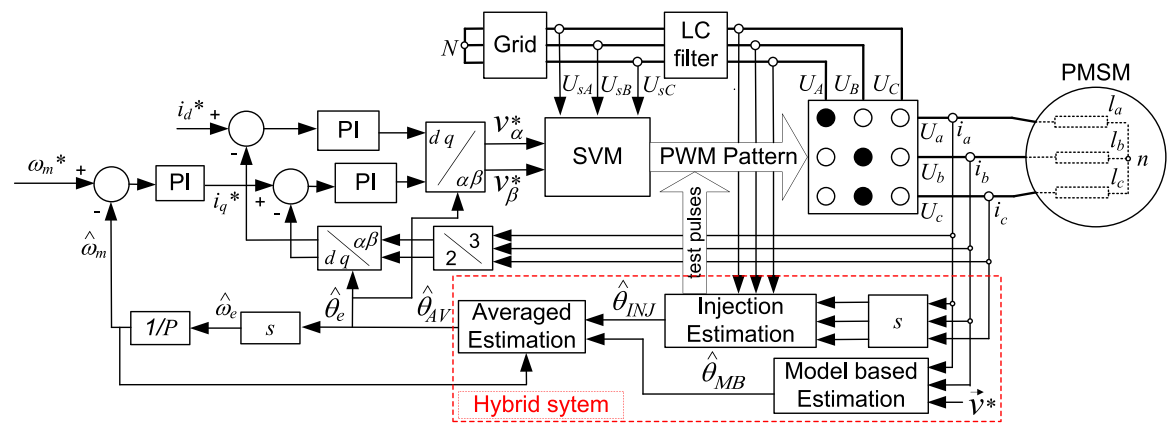

Fig. 8. Hybrid sensorless field-oriented control scheme. 

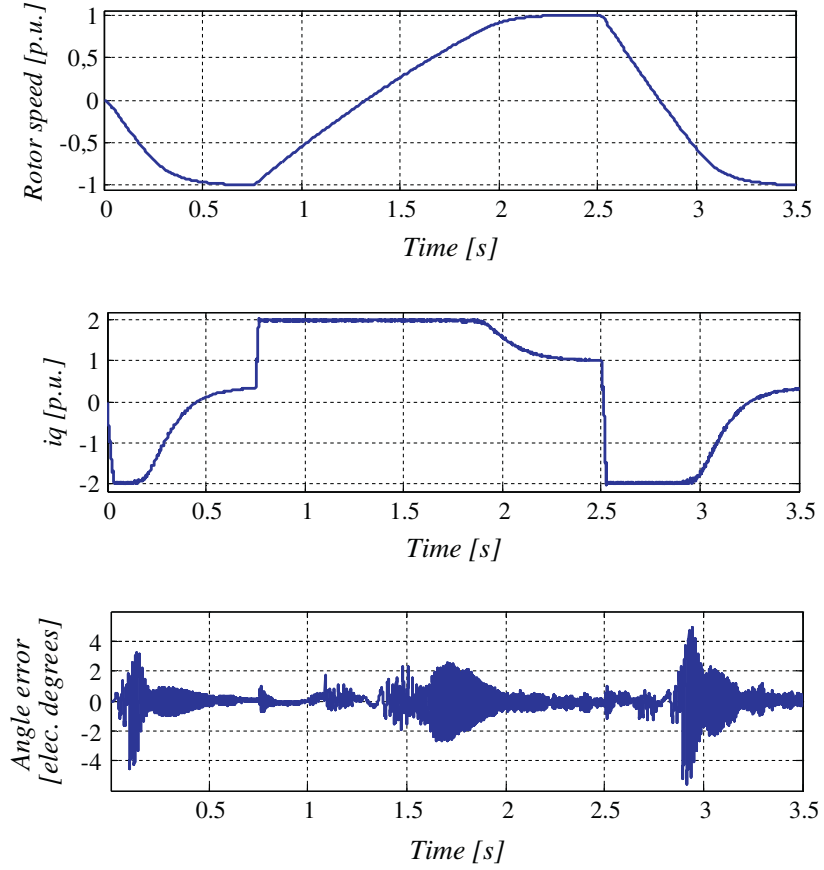

Fig. 10. Sensorless full speed reversal under full load. From top to bottom: estimated speed per unit, quadrature current component per unit and angle error in electrical degrees.
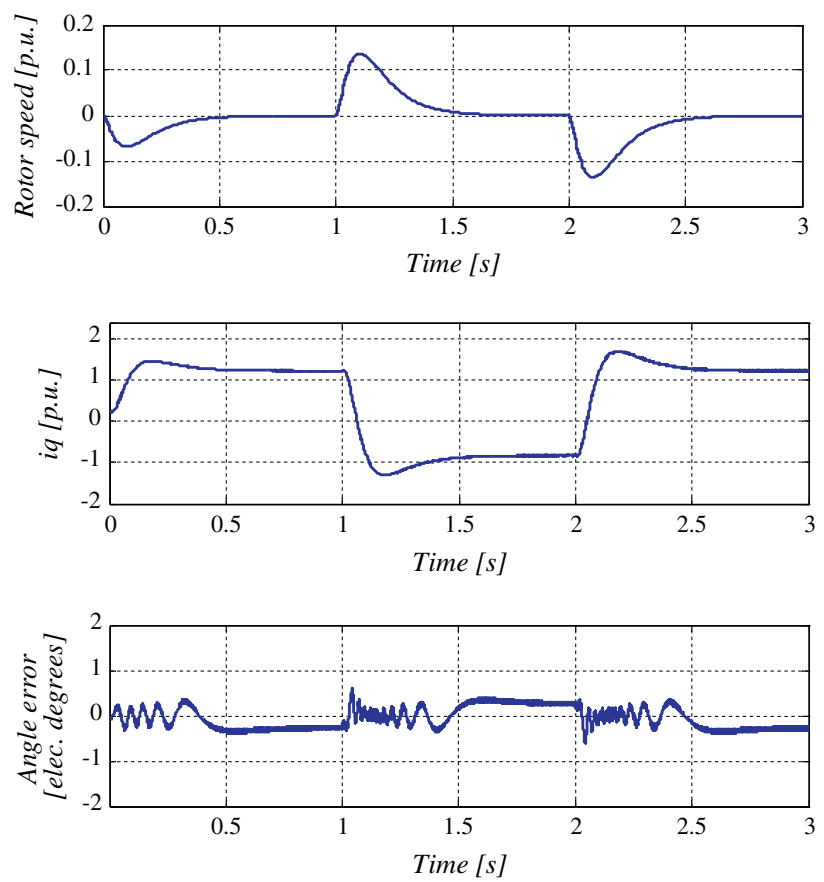

Fig. 11. Full load impact at zero speed. From top to bottom: estimated speed pe unit, quadrature current component per unit and angle error in electrical degrees.

\section{Conclusions}

A hybrid sensorless field-oriented control has been proposed for deriving the estimated permanent magnet angle position at any speed for low-saliency surface-mounted permanent magnet synchronous machines fed by matrix converters. The proposed hybrid sensorless algorithm averages the angle estimations from a wellknown voltage and current model-based estimator, which works
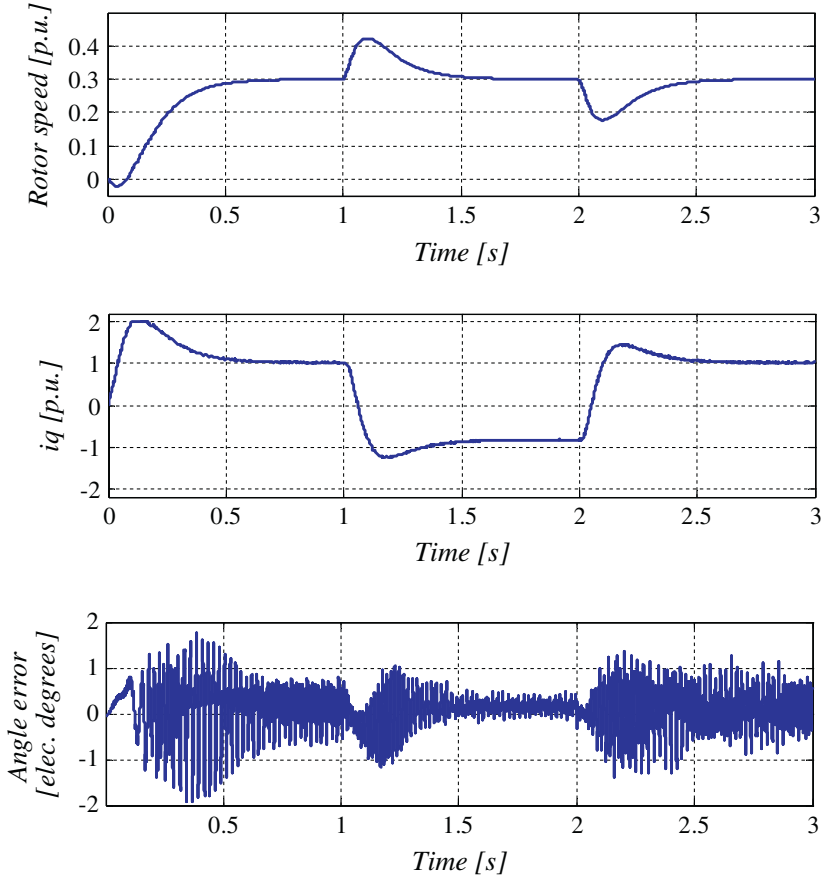

Fig. 12. Full load impact at $30 \%$ speed. From top to bottom: estimated speed per unit, quadrature current component per unit and angle error in electrical degrees.
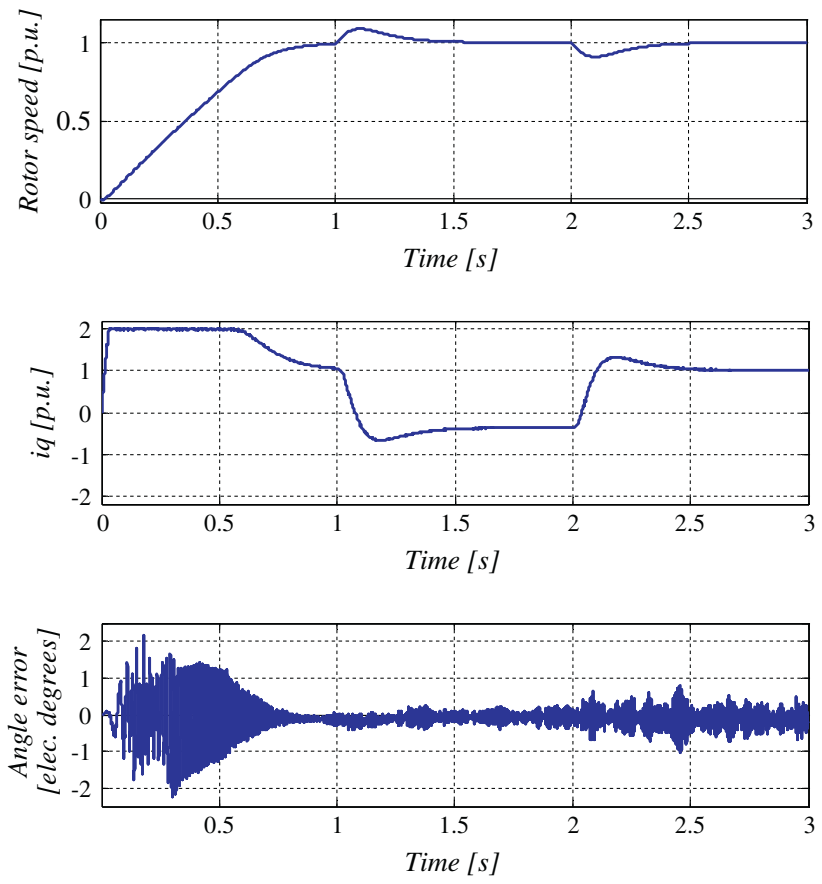

Fig. 13. Full load impact at full speed. From top to bottom: estimated speed per unit, quadrature current component per unit and angle error in electrical degrees.

mainly at high speeds, and from a non-model-based voltage pulse injection technique, which works at zero and low speeds. Another novelty is the use of this voltage pulse injection technique for matrix converters instead of conventional voltage source inverters because several differences exist, which have also been addressed in this research. Hence, not only has the injection algorithm for MC instead of VSI been fully obtained, but lower distortion and losses were also achieved (when compared to the standard VSI) by using lower input voltages for the voltage pulse injection. 


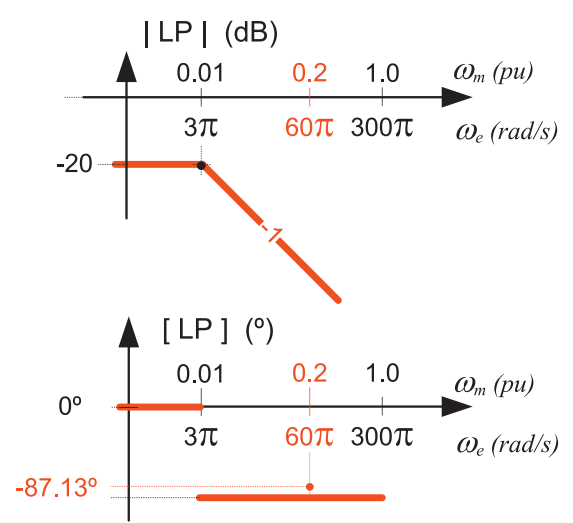

Fig. A1. Low-pass filter for the model-based PM flux vector estimation.

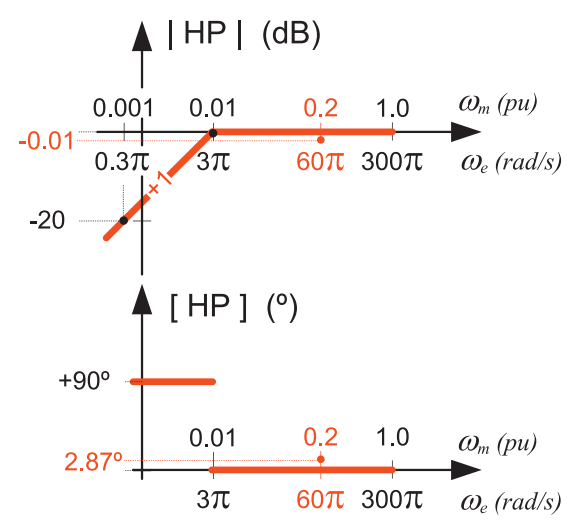

Fig. A2. High-pass filter for the PM flux estimation.

Accurate numerical results that consider the space vector modulation, the matrix converter input filter, the machine's saliency and real plant delays corroborate the proposed hybrid sensorless field-oriented control for all four quadrant operation modes when speed reversal and load impact tests are performed.

\section{Appendix A. LP and HP Filters for the model-based estimation}

Fig. A1 shows the frequency response of the tuned LP first-order filter with a cut-off frequency of $1 \%$ of the nominal speed (see Table 3), which, considering that the PMSM has three pole pairs, gives $3 \pi \mathrm{rad} / \mathrm{s}$ as the electrical angular speed $\left(\omega_{e}\right)$.

In (A1) is given the transfer function of the LP filter in the $s$ and $z$ domains when a sampling period of $80 \mu$ s is used.

$L P(s)=\frac{1}{s+3 \pi} \stackrel{T z=80 \mu \mathrm{s}}{\rightarrow} L P(z)=79.97 \times 10^{-6} \frac{1}{z-0.9992}$

From Eq. (20), applying the LP filter of Eq. (A1), the difference Eq. (A2) can be obtained.

$$
\begin{aligned}
\hat{\vec{\psi}}_{P M L P}(k)= & 0.9992 \cdot \hat{\vec{\psi}}_{P M L P}(k-1)+79.97 \times 10^{-6} \\
& \cdot\left(\vec{v}^{*}(k-1)-r_{s} \cdot \vec{i}(k-1)\right)
\end{aligned}
$$

Fig. A2 shows the HP filter frequency response, and again, the cutoff frequency is fixed at $1 \%$ of the nominal speed, i.e., $3 \pi \mathrm{rad} / \mathrm{s}$ for the magnetic and electrical magnitudes.

Eqs. (A3) and (A4) show the HP filter transfer functions and the difference equation obtained for a sampling period of $80 \mu \mathrm{s}$, respectively.

$$
\begin{aligned}
& H P(s)=\frac{s}{s+3 \pi} \stackrel{\mathrm{Tz}=80 \mu \mathrm{s}}{\rightarrow} H P(z)=\frac{z-1}{z-0.9992} \\
& \hat{\vec{\psi}}_{P M M B}(k)=0.9992 \cdot \hat{\vec{\psi}}_{P M M B}(k-1)+\hat{\vec{\psi}}_{P M L P}(k)-\hat{\vec{\psi}}_{P M L P}(k-1)-l_{q} \cdot \vec{i}(k)
\end{aligned}
$$

\section{References}

[1] Kolar JW, Friedli T, Rodriguez J, Wheeler PW. Review of three-phase PWM ACAC converter topologies. IEEE Trans Ind Electron 2011;58:4988-5006.

[2] Rodriguez J, Rivera M, Kolar JW, Wheeler PW. A review of control and modulation methods for matrix converters. IEEE Trans Ind Electron 2012;59:58-70.

[3] Aten M, Whiltely C, Wheeler PW, Clare JC, Bradley KJ, Towers G. Dynamic performance of a matrix converter driven electro-mechanical actuator for an aircraft rudder. In: IEE PEVD conference; 2004.

[4] Klumpner C, Nielsen P, Boldea I, Blaabjerg F. A new Matrix Converter Motor (MCM) for industry applications. IEEE Trans Ind Electron 2002;49:325-35.

[5] Shapoval I, Clare J, Chekhet E. Experimental evaluation of the variable speed doubly-fed induction machine with matrix converter. Przeglad Elektrotechniczny 2009:115-9.

[6] Hornkamp M, Loddenkoetter M, Muenzer M, Simon O, Bruckmann M. EconoMAC the first all-in-one IGBT module for matrix converters. In: Proceedings PCIM; 2001.

[7] Odaka A, Fujimoto H, Itoh J, Takei M, Igarashi S, Eguchi N, et al. An application technique of a novel IGBT with reverse blocking capability for a direct linked type converter. In: Proceedings of the tenth European conference on power electronics and applications. EPE 2003, CD-ROM, EPE Assoc., Toulouse; 2003.

[8] Yamamoto E, Hara H, Uchino T, Kume TJ, Kang JK, Krug HP. Development of matrix converter and its applications in industry. In: Proceedings of the 2009 IEEE industrial electronics conference. IECON 2009, CD-ROM, Porto, Portugal.

[9] Widyan Mohammad S, Hanitsch Rolf E. High-power density radial-flux permanent-magnet sinusoidal three-phase three-slot four-pole electrical generator. Int J Electr Power Energy Syst 2012;43:1221-7.

[10] Maiti S, Chakraborty C, Sengupta S. Simulation studies on model reference adaptive controller based speed estimation technique for the vector controlled permanent magnet synchronous motor drive. Simul Model Practice Theory 2008. http://dx.doi.org/10.1016/j.simpat.2008.08.017.

[11] Krzeminski Z. Speed observers based on extended models of induction motor. Przeglad Elektrotechniczny 2009:141-7.

[12] Öztürk Nihat, Celik Emre. Speed control of permanent magnet synchronous motors using fuzzy controller based on genetic algorithms. Int J Electr Power Energy Syst 2012;43:889-98.

[13] Aydogmus O, Sünter S. Implementation of EKF based sensorless drive system using vector controlled PMSM fed by a matrix converter. Int J Electr Power Energy Syst 2012;43:736-43.

[14] Chen Chiung Hsing, Hong Chih-Ming, Cheng Fu-Sheng. Intelligent speed sensorless maximum power point tracking control for wind generation system. Int J Electr Power Energy Syst 2012;42:399-407.

[15] Silva C, Asher GM, Sumner M, Bradley KJ. Sensorless control in a surface mounted PM machine using rotating injection. In: Proceedings of the tenth European conference on power electronics and applications. EPE 2003, CDROM, EPE Assoc., Toulouse; 2003.

[16] Arias A, Silva C, Asher GM, Clare JC, Wheeler PW. Use of a matrix converter to enhance the sensorless control of a surface-mount permanent-magnet $\mathrm{AC}$ motor at zero and low frequency. IEEE Trans Ind Electron 2006;53:440-9.

[17] Jansen PL, Lorenz RD. Transducerless position and velocity estimation in induction and salient AC machines. IEEE Trans Ind Appl 1995;31:240-7.

[18] Kim J-S, Sul S-K. High performance PMSM drives without rotational position sensors using reduced order observer. In: Industry applications conference 1995. Conference record of the IEEE; 1995. p 75-82.

[19] Staines CS, Caruana C, Asher GM, Sumner M. Sensorless control of induction machines at zero and low frequency using zero sequence currents. IEEE Trans Ind Electron 2006;53:195-206.

[20] Holtz J, Juliet J. Sensorless acquisition of the rotor position angle of induction motors with arbitrary stator windings. IEEE Trans Ind Appl 2005;41:1675-82.

[21] Ha J-I, Kang S-J, Sul S-K. Position-controlled synchronous reluctance motor without rotational transducer. IEEE Trans Ind Appl 1999;35:1393-8.

[22] Schroedl M, Weinmeier P. Sensorless control of reluctance machines at arbitrary operating conditions including standstill. IEEE Trans Power Electron 1994;9:225-31.

[23] Capecchi E, Guglielmi P, Pastorelli M, Vagati A. Position sensorless control of transverse-laminated synchronous reluctance motor. IEEE Trans Ind Appl 2001;37:1768-76

[24] Silva C, Asher GM, Sumner M. Hybrid rotor position observer for wide speedrange sensorless pm motor drives including zero speed. IEEE Trans Indus Electron 2006;53:373-8.

[25] Kolar J, Frielli T, Krismer F, Round S. The essence of three phase AC/AC converter system. Przeglad Elektrotechniczny 2008:14-29.

[26] Baroudi JA, Dinavahi V, Knight AM. A review of power converter topologies for wind generators. Elsevier Renew Energy 2007;32:2369-85. 
[27] Klumpner C, Blaabjerg F, Nielsen P. Speeding-up the maturation process of the matrix converter technology. Proceedings of the IEEE 32nd annual power electronics specialists conference, vol. 2. NJ, USA: Piscataway; 2001. p. 1083-8.

[28] Andreu J, de Diego JM, de Alegría IM, Kortabarria I, Martín JL, Ceballos S. New protection circuit for high-speed switching and start-up of a practical matrix converter. IEEE Trans Ind Electron 2008;55:3100-14.

[29] Ramboz JD. Machinable rogowski coil, design and calibration. IEEE Trans Instrum Meas 1996;45:511-5.

[30] Arias A, Ortega C, Pou J, Gonzalez D, Balcells J. Angle estimation for sensorless field oriented control with matrix converters and surface moun permanent magnet synchronous machines. In: Proceedings of the IEEE 39th annual power electronics specialists conference. Rhodes, Greece; 2008. p. 3659-64.
[31] Casadei D, Serra G, Tani A, Zarri L. Matrix converter modulation strategies: a new general approach based on spacevector representation of the switch state. IEEE Trans. Ind. Electron. 2002;49:370-81.

[32] Gao Q Asher GM, Sumner M, Makys P. Sensorless control of induction machines, including zero frequency using only fundamental PWM excitation. In: Proceedings of the 2006 IEEE industrial electronics conference. IECON 2006, Paris, France; p 793-98.

[33] Arias A, Aldabas E, Ortega C, Zaragoza J, Pou J, Jaen C. Permanent magnet synchronous motor sensorless control using pulse test shorter voltages matrix converters vectors. In: Proceedings of the 2008 IEEE international symposium on industrial electronics. ISIE 2008, Cambridge, United Kingdom. CR-ROM.

[34] Kazmierkowski MP, Tunia H. Automatic control of converter-fed drives. Elsevier Science Publishers, B.V.; 1994. 